\title{
Analisis Sirkulasi dan Jalur Penghubung Kawasan Pecinan Kota Lama Tangerang
}

\author{
Manisa Edelin Jingga ${ }^{a}$, Lintang Suminar ${ }^{b^{*}}$ \\ ${ }^{\text {a b }}$ Program Studi Perencanaan Wilayah dan Kota, Fakultas Teknik, Universitas Sebelas Maret, Surakarta, Indonesia
}

Keywords: circulation connecting lanes chinatown
Kata kunci:

sirkulasi

jalur penghubung

kawasan pecinan

\begin{abstract}
The circulation system and city connecting lanes have a role in optimizing the use of roads that will provide convenience and security for road users. Tangerang City is a city that is experiencing rapid growth, one of which is influenced by its strategic location close to Jakarta as the nation's capital. The high growth in Tangerang City is also directly proportional to the increase in demand for roads to accommodate traffic activities, including the effect on circulation conditions. The research location is the Chinatown area of Kota Lama Tangerang which is located in 3 (three) urban villages, namely Sukasari, Sukarasa, and Sukaasih villages. The Chinatown area of Kota Lama Tangerang is an area of culture, trade and services, offices, and housing. The Chinatown area in Kota Lama is the forerunner of the center of Tangerang City or can even be called the city's zero point because it is in this area that the center of Tangerang City was formed. This study aims to analyze the circulation and connecting lanes of the Chinatown area of Kota Lama Tangerang which consists of road network analysis and movement, vehicle circulation analysis, transit movement analysis, parking system analysis, and pedestrian and bicycle lane analysis. The research method used is a qualitative method. The research approach used is descriptive with data collection through observation which is then translated into documentation, mapping, and description. The results of the study concluded that there is a need for improvement and rearrangement of the area so that it becomes more integrated and can support the area to become a tourism object.
\end{abstract}

\section{ABSTRAK}

Sistem sirkulasi dan jalur penghubung kota memiliki peran dalam optimalisasi pemanfaatan jalan yang akan memberikan kemudahan dan keamanan bagi pemakai jalan. Kota Tangerang merupakan kota yang mengalami pertumbuhan pesat, salah satunya dipengaruhi faktor lokasi yang strategis berdekatan dengan Jakarta sebagai ibu kota Negara. Tingginya pertumbuhan di Kota Tangerang turut berbanding lurus dengan peningkatan permintaan terhadap jalan untuk menampung kegiatan lalu lintas, termasuk juga berpengaruh pada kondisi sirkulasi. Lokasi penelitian yaitu Kawasan Pecinan Kota Lama Tangerang yang berada pada 3 (tiga) kelurahan, yaitu kelurahan Sukasari, Sukarasa, dan Sukaasih. Kawasan Pecinan Kota Lama Tangerang merupakan kawasan budaya, perdagangan dan jasa, perkantoran, dan perumahan. Kawasan Pecinan di Pasar Lama merupakan cikal bakal pusat Kota Tangerang atau bahkan dapat disebut sebagai zero point kota karena di kawasan inilah pusat Kota Tangerang terbentuk. Penelitian ini bertujuan untuk menganalisis sirkulasi dan jalur penghubung Kawasan Pecinan Kota Lama Tangerang yang terdiri dari analisis jaringan jalan dan pergerakan, analisis sirkulasi kendaraan, analisis pergerakan transit, analisis sistem parkir, dan analisis jalur pejalan kaki dan jalur sepeda. Metode penelitian yang digunakan adalah metode kualitatif. Pendekatan penelitian yang digunakan yaitu deskriptif dengan pengumpulan data melalui observasi yang kemudian diterjemahkan dalam dokumentasi, pemetaan, dan deskripsi. Hasil penelitian menyimpulkan perlunya perbaikan dan penataan ulang kawasan agar menjadi lebih terintegrasi dan dapat mendukung kawasan menjadi obyek pariwisata.

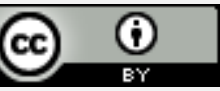

This is an open access article under the CC-BY license. 


\section{Pendahuluan}

Kota Tangerang merupakan kota yang letaknya sangat strategis karena bersinggungan langsung dengan Ibukota Negara yaitu DKI Jakarta. Posisi tersebut menjadikan Kota Tangerang mengalami pertumbuhan yang sangat pesat. Pertumbuhan yang terjadi akibat peningkatan aktivitas kota berkaitan erat dengan kegiatan ekonomi dan transportasi [1]. Pertambahan penduduk dan peningkatan kepemilikan kendaraan akan berbanding lurus dengan peningkatan permintaan terhadap jalan untuk menampung kegiatan lalu lintas [2].

Jalan digunakan sebagai ruang yang melibatkan aksi dan reaksi, ruang pergerakan untuk menemukan tempat/tujuan, ruang untuk saling bertemu dan berinteraksi, ruang untuk aktivitas rekreasi, dan sebagai ruang apresiasi nilai-nilai sejarah [3]. Dengan demikian, jalan memegang peranan yang penting sebagai ruang publik perkotaan dan berfungsi untuk menyediakan wadah bagi kehidupan bersama di suatu kota [3][4].

Sirkulasi merupakan salah satu faktor yang berpengaruh terhadap kenyamanan pengguna jalan [5]. Sistem sirkulasi dan jalur penghubung terdiri dari jaringan jalan dan pergerakan, sirkulasi kendaraan umum, sirkulasi kendaraan pribadi, sirkulasi kendaraan informal setempat dan sepeda, sirkulasi pejalan kaki (termasuk masyarakat penyandang cacat dan lanjut usia), sistem dan sarana transit, sistem parkir, perencanaan jalur pelayanan lingkungan, dan sistem jaringan penghubung. Sistem sirkulasi dan jalur penghubung memiliki manfaat untuk mengoptimalkan efisiensi pemanfaatan prasarana jalan dengan jenis arus pergerakan yang terjadi; mendapatkan distribusi atau penyebaran pergerakan yang selaras dengan jenis aktivitas yang diwadahi sehingga dicapai ketertiban; dan mencapai kinerja fungsi serta keseimbangan, kaitan, keterpaduan dari berbagai elemen pergerakan, lingkungan dan sosial, antara kawasan perencanaan dan lahan di luarnya [6]. Kejelasan dan kenyamanan dalam sirkulasi akan memberikan kemudahan dan keamanan bagi para pemakainya [7]. Hal tersebut dipengaruhi oleh dimensi kendaraan. Peningkatan komposisi kendaraan akan mengakibatkan penumpukan kendaraan dan penyempitan ruang jalan yang berdampak pada penurunan kapasitas jalan tersebut [8].

Budaya dan masyarakat Tionghoa di Indonesia telah lama menjadi bagian dari budaya bangsa. Hal yang menarik terhadap keberadaan golongan etnis Tionghoa di Indonesia adalah munculnya komunitas-komunitas Tionghoa di Indonesia yang hampir tersebar di setiap kota besar. Mereka umumnya mendiami tempat yang disebut
Kampung Pecinan, salah satunya ialah keberadaan komunitas Tionghoa yang terdapat di Kota Tangerang. Secara umum, masyarakat akan memilih untuk mengunjungi kawasan yang dapat memenuhi kebutuhan mereka ataupun kebutuhan masyarakat luas. Dari perkembangan suatu kota terkait kawasan pusat perdagangan yang strategis merupakan salah satu hal yang diminati masyarakat untuk melakukan berbagai jenis kegiatan. Tumbuhnya kegiatan perekonomian di Kawasan Pecinan Kota Lama Tangerang berpotensi menimbulkan bangkitan dan tarikan yang tinggi.

Kawasan Pecinan Kota Lama Tangerang merupakan salah satu kawasan bersejarah sebagai wajah kuno dari Kota Tangerang. Kawasan Pecinan Kota Lama Tangerang memiliki fungsi kawasan campuran yang terdiri dari kawasan perdagangan dan jasa, aktivitas dan kegiatan ekonomi serta kawasan perumahan atau permukiman. Kawasan Pecinan Kota Lama Tangerang turut didukung dengan fasilitas transportasi umum yang menghubungkan dengan beberapa lokasi disekitar Kota Tangerang dan Kota Jakarta. Secara keseluruhan dengan keberadaan Sungai Cisadane, bangunan bersejarah, serta aktivitas/budaya masyarakat di dalamnya menjadi daya tarik tersendiri dari kawasan pecinan ini. Kawasan ini berada di Jalan Kisamaun, yang memiliki peranan utama dalam pengembangan Kawasan Pecinan Kota Lama Tangerang sebagai kawasan pariwasata karena berperan sebagai akses utama pencapaian dari segala arah lokasi dan menyebabkan adanya bangkitan dan tarikan menuju kawasan. Mobilitas menuju dan keluar dari Kawasan Pecinan Kota Lama Tangerang terbilang cukup padat, maka dibutuhkan sistem sirkulasi dan jalur penghubung untuk mengatur aksesibiltas yang tinggi di Kawasan Pecinan Kota Lama Tangerang.

\section{Metode}

\subsection{Lokasi Penelitian}

Lokasi penelitian berada di Kawasan Pecinan Kota Lama Tangerang. Kawasan Pecinan Kota Lama Tangerang merupakan kawasan budaya, perdagangan dan jasa, perkantoran, dan perumahan. Kawasan Pecinan Kota Lama merupakan cikal bakal pusat Kota Tangerang atau bahkan dapat disebut sebagai zero point kota karena di kawasan inilah pusat Kota Tangerang terbentuk. Secara administratif, Kawasan Pecinan Kota Lama Tangerang termasuk dalam wilayah kecamatan Tangerang. Lokasi kawasan ini berada pada 3 (tiga) kelurahan, yaitu Kelurahan Sukasari, Kelurahan Sukarasa, dan Kelurahan Sukaasih. Salah satu ruas jalan yang melintasi kawasan tersebut adalah Jalan Kisamaun. Jalan Kisamaun 
merupakan koridor jalan dengan fungsi perdagangan dan jasa serta aktivitas atau kegiatan ekonomi usaha kecil dan menegah. Ruas Jalan Kisamaun memiliki fungsi ruas jalan sebagai jalan kolektor sekunder. Jalan Kisamaun memiliki rute dengan satu arah lalu lintas. Jalan Kisamaun merupakan jalur utama untuk memasuki Kawasan Pecinan Kota Lama Tangerang dan berpotensi memiliki intensitas kendaraan yang tingi karena adanya berbagai aktivitas di sekitarnya.

\subsection{Metode Penelitian}

Pengumpulan data dilakukan melalui observasi lapangan. Observasi dalam penelitian dilakukan dengan pengamatan terhadap kondisi eksisting sirkulasi kawasan yang kemudian dianalisis secara deskriptif kualitatif. Adapun analisis dalam penelitian ini terdiri dari analisis jaringan jalan dan pergerakan, analisis sirkulasi kendaraan, analisis pergerakan transit, analisis sistem parkir, dan analisis jalur pejalan kaki dan jalur sepeda. Analisis dilakukan melalui deskripsi data, menganalisis kondisi, penyebab, dan permasalahan yang terjadi, sehingga dapat disimpulkan saran yang sesuai untuk pengembangan sirkulasi dan jalur penghubung Kawasan Pecinan Kota Lama Tangerang.
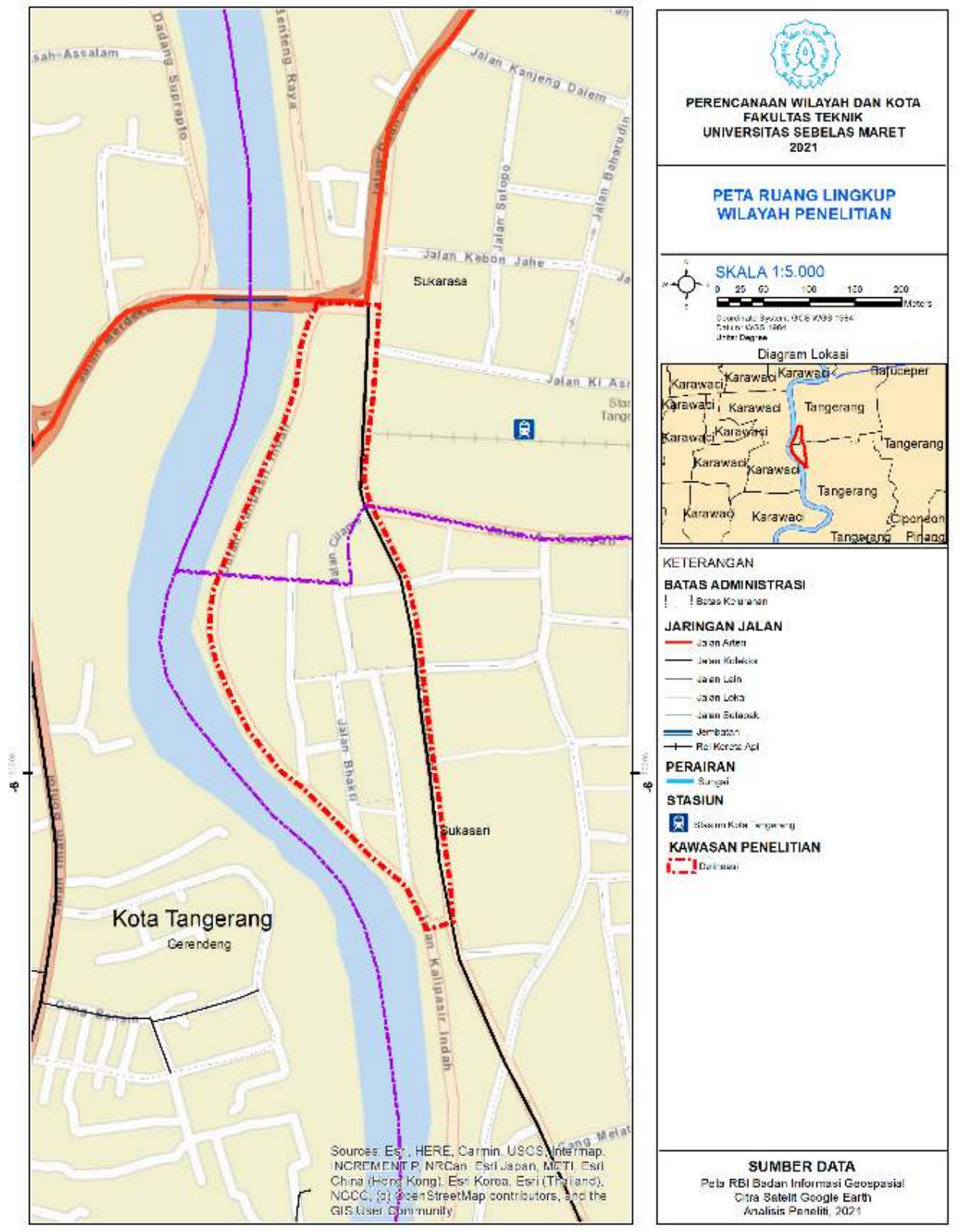

Gambar 1. Peta Deliniasi Kawasan Pecinan Kota Lama Tangerang 


\section{Hasil dan Pembahasan}

\subsection{Analisis Jaringan Jalan dan Pergerakan}

Untuk mendukung kemudahan dalam melakukan aktivitas, aksesibilitas merupakan salah satu faktor utama yang harus diperhatikan. Jaringan jalan di Kawasan Pecinan Kota Lama Tangerang terdiri dari jalan kolektor sekunder. Jalan kolektor sekunder berada pada Jalan Kisamaun. Jalan ini memiliki perkerasan aspal dengan lebar 14,5meter yang terbagi menjadi 4 lajur. Dari 4 lajur tersebut, 2 lajur digunakan lalu lintas kendaraan dan lajur lainnya digunakan sebagai on-street parking. Maka, dengan kondisi jaringan jalan yang terbatas dan padat kendaraan dapat menimbulkan kemacetan. Selain itu, Jalan Kisamaun berperan sebagai akses utama kawasan pecinan sebagai kawasan kuliner pasar lama Kota Tangerang yang ditandai dengan adanya gapura sebagai penanda untuk masuk ke Kawasan Pecinan Kota Lama Tangerang dan dilengkapi oleh jembatan penyebrangan untuk memudahkan aksesibilitas antara Jalan KisamaunJalan Daan Mogot-Jalan Merdeka.

\subsection{Analisis Sirkulasi Kendaraan}

Sirkulasi kota meliputi prasarana jalan yang tersedia, bentuk struktur kota, fasilitas pelayanan umum, dan jumlah kendaraan bermotor yang semakin meningkat. Sirkulasi kendaraan di Kawasan Pecinan Kota Lama Tangerang terbilang cukup lancar pada saat weekday atau hari kerja. Kemacetan di kawasan ini menjadi permasalahan utama pada saat weekend atau akhir pecan/masa libur. Kemacetan disebabkan karena adanya pedagang kaki lima (PKL) yang beroperasi dan adanya on street parking di ruas Jalan Kisamaun sehingga menyebabkan terganggunya sirkulasi kendaraan di Kawasan Pecinan Pasar Lama Kota Tangerang. Akses ke dalam kawasan pecinan cukup mudah, karena letaknya berada di pusat Kota Tangerang.
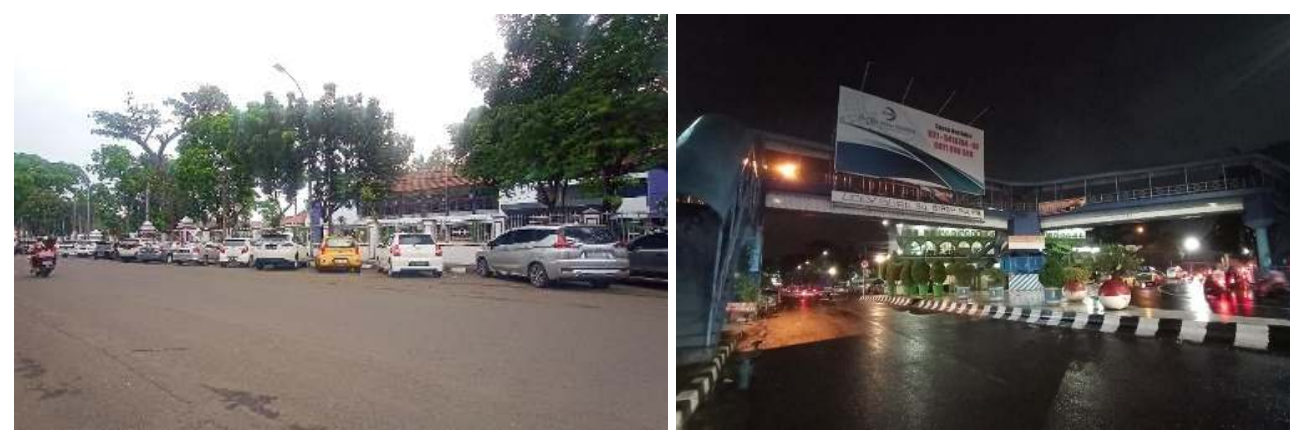

Gambar 2. Kondisi Eksisting Jalan Kolektor Sekunder Jalan Kisamaun

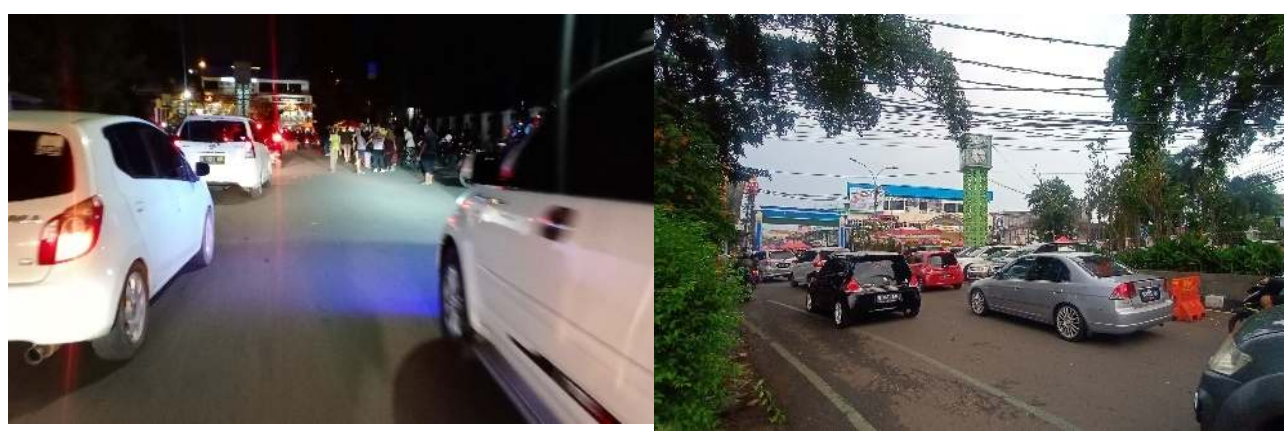

Gambar 3. Kondisi Eksisting Sirkulasi Kawasan Pecinan Kota Lama Tangerang 


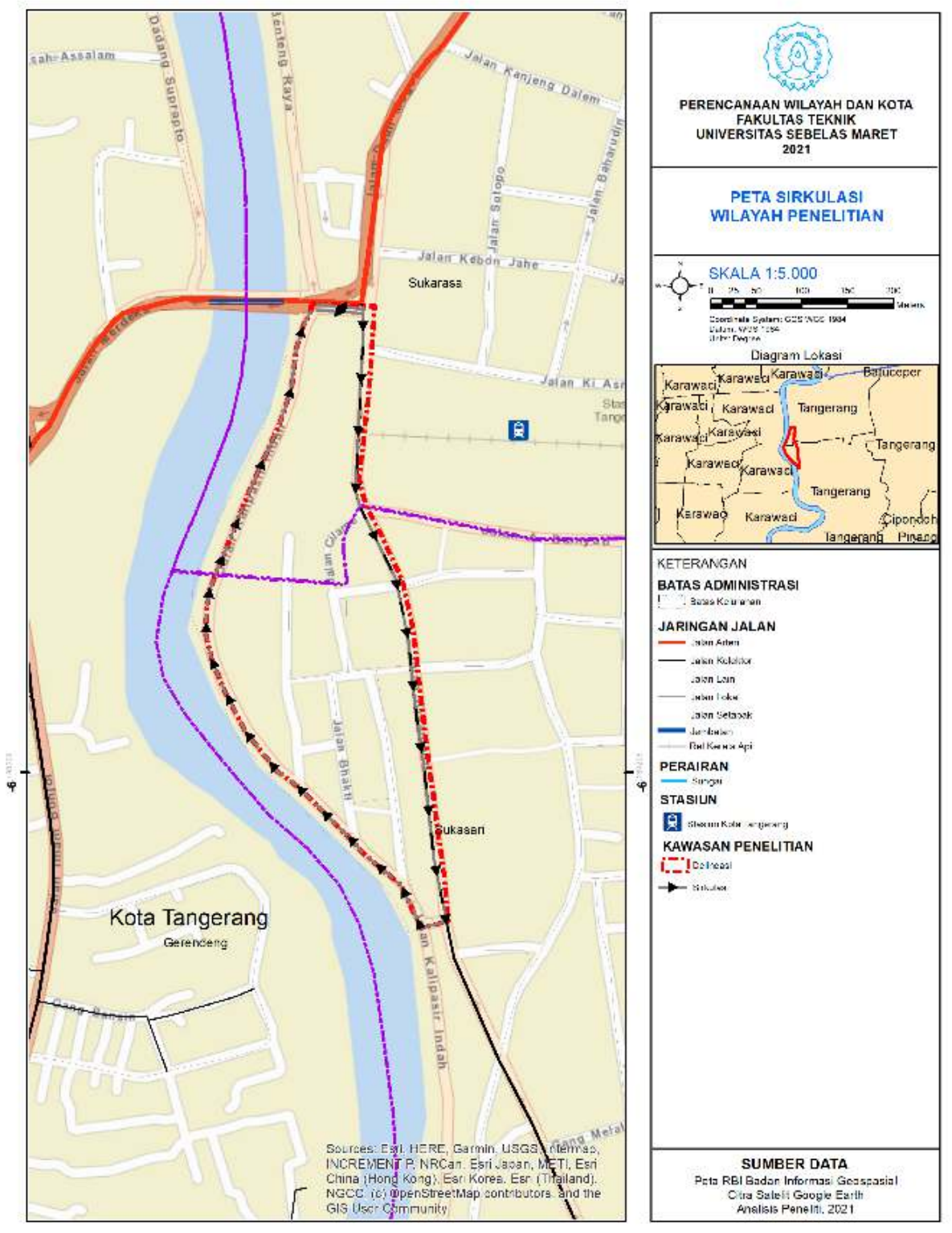

Gambar 4. Peta Sirkulasi Kawasan Pecinan Kota Lama Tangerang

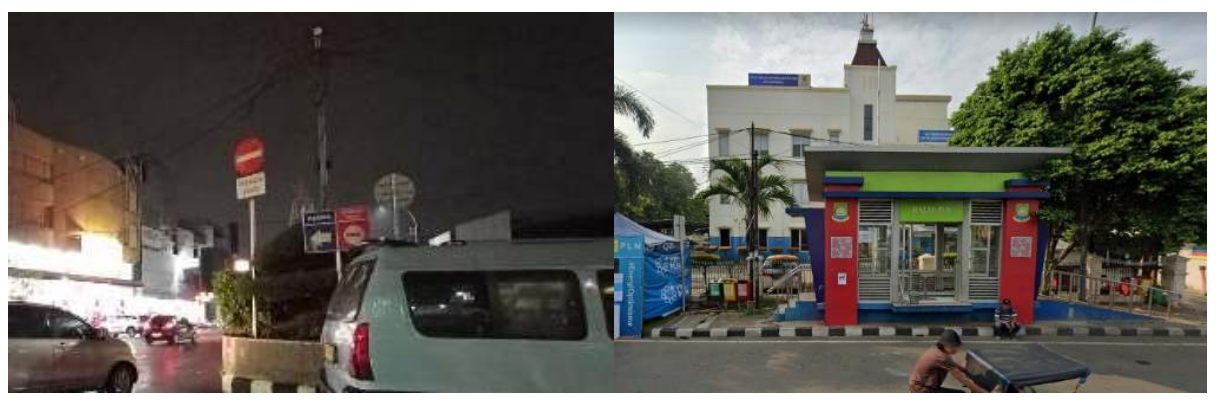

Gambar 5. Titik Pergerakan Transit Kawasan Pecinan Kota Lama Tangerang

\subsection{Analisis Pergerakan Transit}

Untuk mencapai Kawasan Pecinan Kota Lama Tangerang dapat diakses menggunakan transportasi umum seperti commuter line (KRL), bus Trans Tangerang, dan angkutan kota. Pergerakan transit ini sudah didukung dengan keberadaan simpul berupa Stasiun Kota Tangerang yang terjangkau oleh pengguna dari luar Kota Tangerang, dan hanya berjarak 450meter dari kawasan pecinan sehingga masih terjangkau oleh pejalan kaki. 
Pada kawasan juga terdapat halte bus untuk transit pengunjung yang menggunakan trans tangerang, namun letaknya cukup jauh dari kawasan pecinan. Terdapat pula titik kumpul angkutan kota yang letaknya tepat di ujung Jalan Kisamaun. Walaupun pergerakan transit sudah tersedia di dalam maupun luar kawasan, namun masih ada beberapa angkutan kota yang berhenti tidak tertib sehingga mengganggu kelancaran arus lalu lintas.

\subsection{Analisis Sistem Parkir}

Kawasan Pecinan Kota Lama Tangerang memiliki mobilitas yang tinggi. Keberadaan Sungai Cisadane, bangunan bersejarah, serta aktivitas/budaya masyarakat di kawasan ini menjadi daya tarik yang menimbulkan bangkitan dan tarikan kawasan. Semakin meningkatnya jumlah aktivitas dan kendaraan, maka tempat parkir sangat dibutuhkan terutama pada pusat kegiatan kota.

Tempat parkir di Kawasan Pecinan Kota Lama Tangerang menggunakan sistem on street parking. Sistem parkir di kawasan ini menggunakan ruas Jalan Kisamaun dan Jalan Kalipasir Indah sebagai tempat parkir kendaraan. Namun, sistem on street parking tersebut menyebabkan kemacetan di saat arus lalu lintas sedang ramai dan juga karena adanya pedagang kaki lima yang beroperasi tidak jauh dari tempat parkir tersebut. Sistem parkir di kawasan pecinan ini melebih kapasitas yang disediakan, sehingga menyebabkan beberapa parkir liar yang terbentuk. Parkir liar ini terdapat di jalan utama maupun di gang-gang masuk kedalam permukiman masyarakat kawasan pecinan.

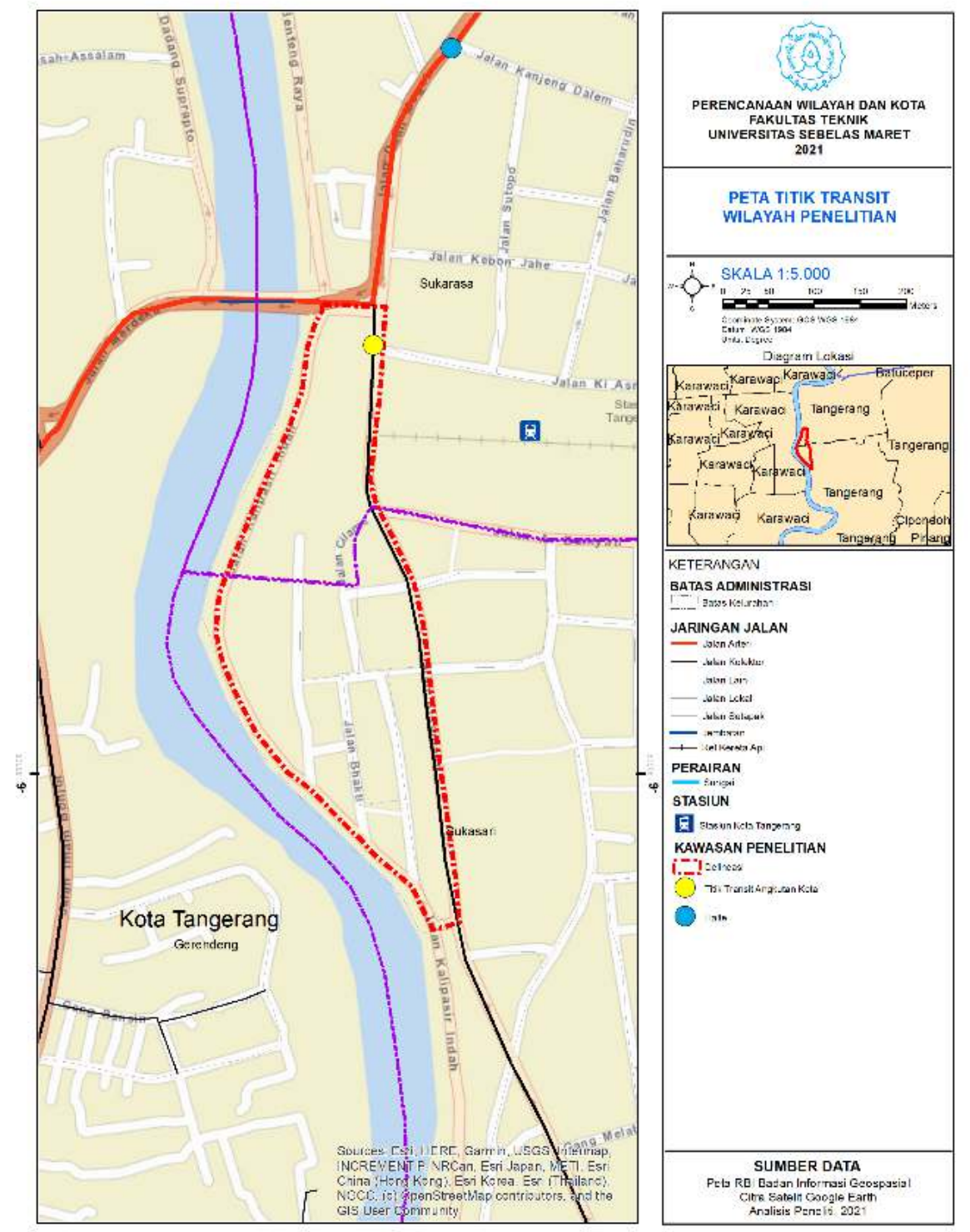

Gambar 6. Peta Titik Transit Kawasan Pecinan Kota Lama Tangerang 


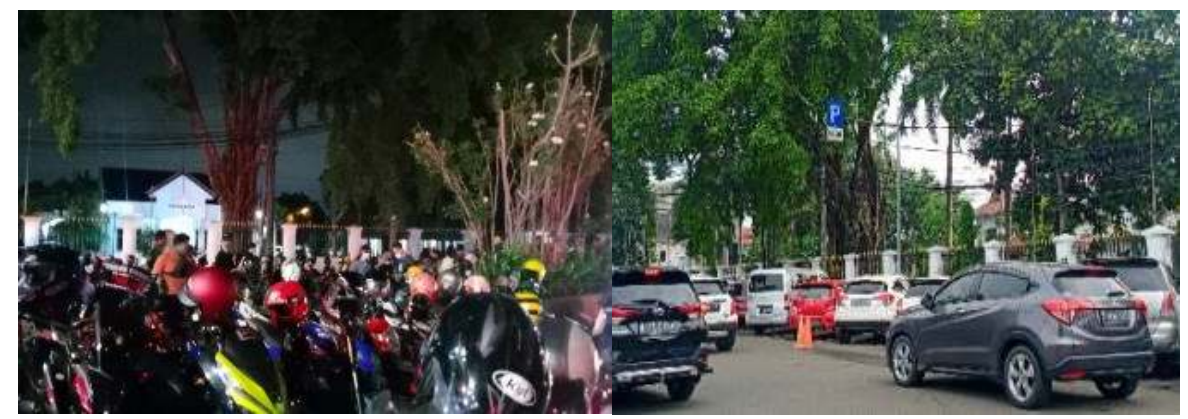

Gambar 7. Kondisi Eksisting Sistem Parkir di Jalan Kisamaun
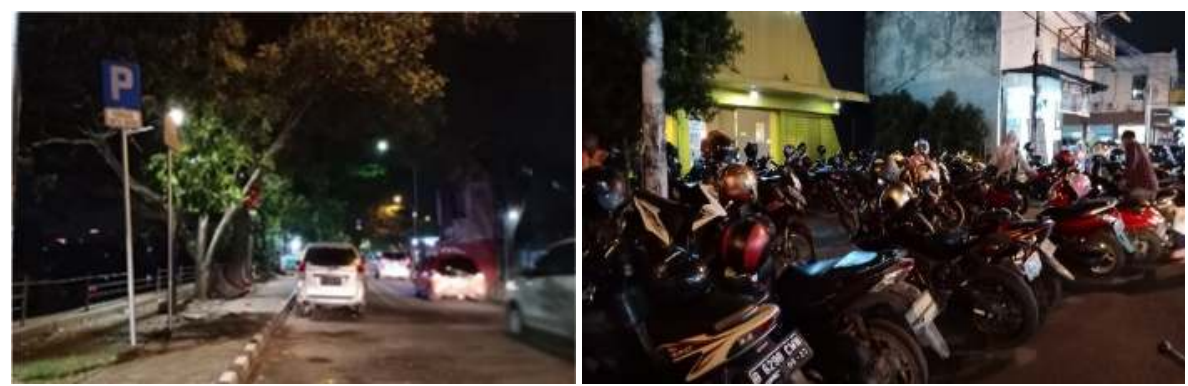

Gambar 8. Kondisi Eksisting Sistem Parkir di Jalan Kalipasir Indah

Gambar 8 dan Gambar 9 menunjukkan kondisi sistem parkir di Kawasan Pecinan Kota Lama Tangerang. On street parking terjadi karena keterbatasan lahan di dalam kawasan, sedangkan jumlah pengguna atau pengunjung cenderung tinggi mengingat kawasan tersebut juga sebagai kawasan wisata.

\subsection{Analisis Jalur Pejalan Kaki dan Jalur Sepeda}

Sistem pejalan kaki salah satunya bertujuan untuk mengurangi ketergantungan terhadap kendaraan bermotor. Elemen jalur pejalan kaki merupakan elemen dasar desain tata kota dan berkaitan dengan lingkungan kota dan pola aktivitas masyarakat yang sesuai dengan perubahan dan pembangunan fisik kota. Jalur pejalan kaki di Kawasan Pecinan Kota Lama Tangerang terbagi menjadi jalur pejalan kaki pada zona kuliner dan zona ruang terbuka karena dua zona tersebut merupakan zona yang cenderung lebih menarik minat pengunjung. Jalur pejalan kaki pada zona kuliner saat ini sudah tersedia, namun jalur ini digunakan oleh pedagang kaki lima (PKL) untuk berjualan, sehingga menyebabkan terganggunya aktivitas pejalan kaki.

Sedangkan pada zona ruang terbuka yang berada di tepi sungai Cisadane, telah tersedia jalur pejalan kaki yang digunakan oleh masyarakat untuk berjalan-jalan serta menikmati pemandangan Sungai Cisadane di sepanjang jalur tersebut. Jalur pejalan kaki tersebut juga dilengkapi oleh pepohonan yang rindang sehingga menambah kenyamanan bagi pejalan kaki. Namun, pada jalur ini belum dilengkapi oleh street furniture yang memadai dan dapat menambah aktivitas masyarakat. Hal tersebut tentu juga akan berpengaruh pada kenyamanan pejalan kaki yang menggunakan jalur tersebut.

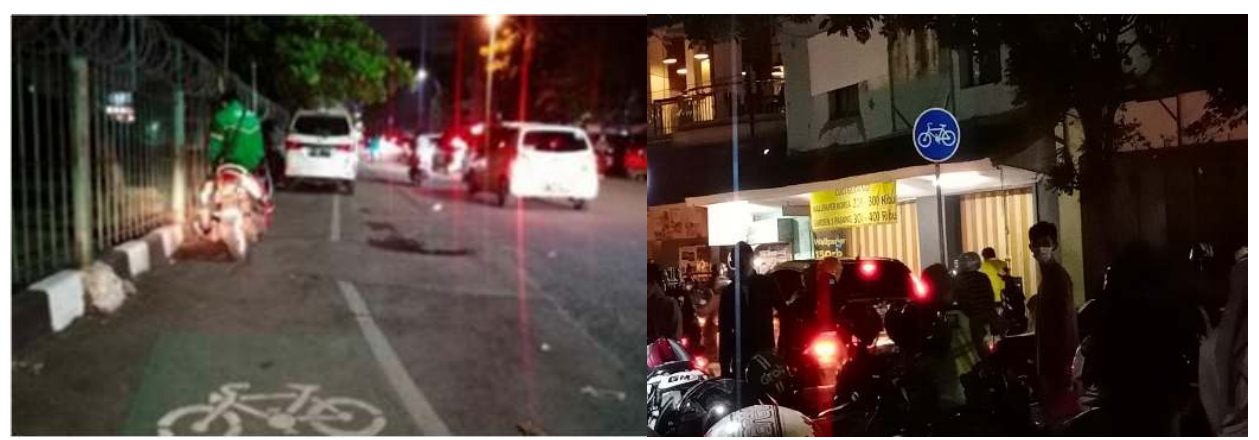

Gambar 9. Kondisi Eksisting Jalur Sepeda di Kawasan Pecinan Kota Lama Tangerang 


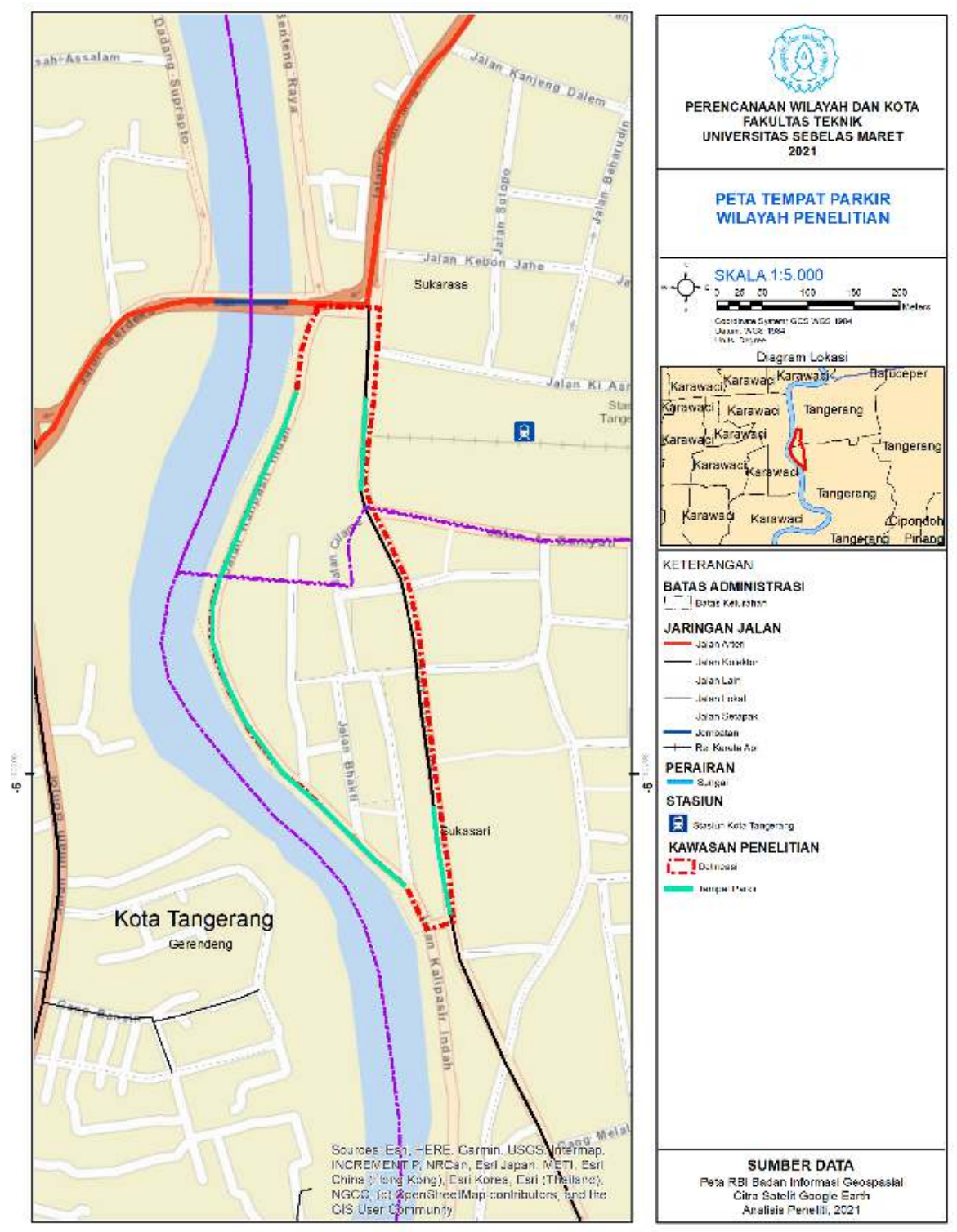

Gambar 10. Peta Lokasi Parkir Kawasan Pecinan Kota Lama Tangerang

Jalur sepeda pada Kawasan Pecinan Kota Lama Tangerang hanya tersedia di Jalan Kisamaun di samping stasiun Kota Tangerang menuju Jalan Ahmad Yani dan belum tersedia di dalam Zona Kuliner. Jalur sepeda ini difasilitasi oleh pemerintah Kota Tangerang untuk para pesepeda agar tetap merasa aman dan nyaman.

Gambar 14 menunjukkan kondisi eksisting jalur sepeda di Kawasan Pecinan Kota Lama Tangerang. Dapat dilihat bahwa pada kondisi-kondisi tertentu, utamanya pada malam hari, jalur sepeda tidak berfungsi sebagaimana mestinya. Jalur sepeda di Kawasan Pecinan Kota Lama Tangerang banyak digunakan sebagai area parkir kendaraan baik roda dua maupun roda empat. Hal tersebut tentu seharusnya menjadi perhatian khusus karena pesepeda juga memiliki hak yang sama dengan pengguna jalan lain termasuk pengguna kendaraan bermotor. 

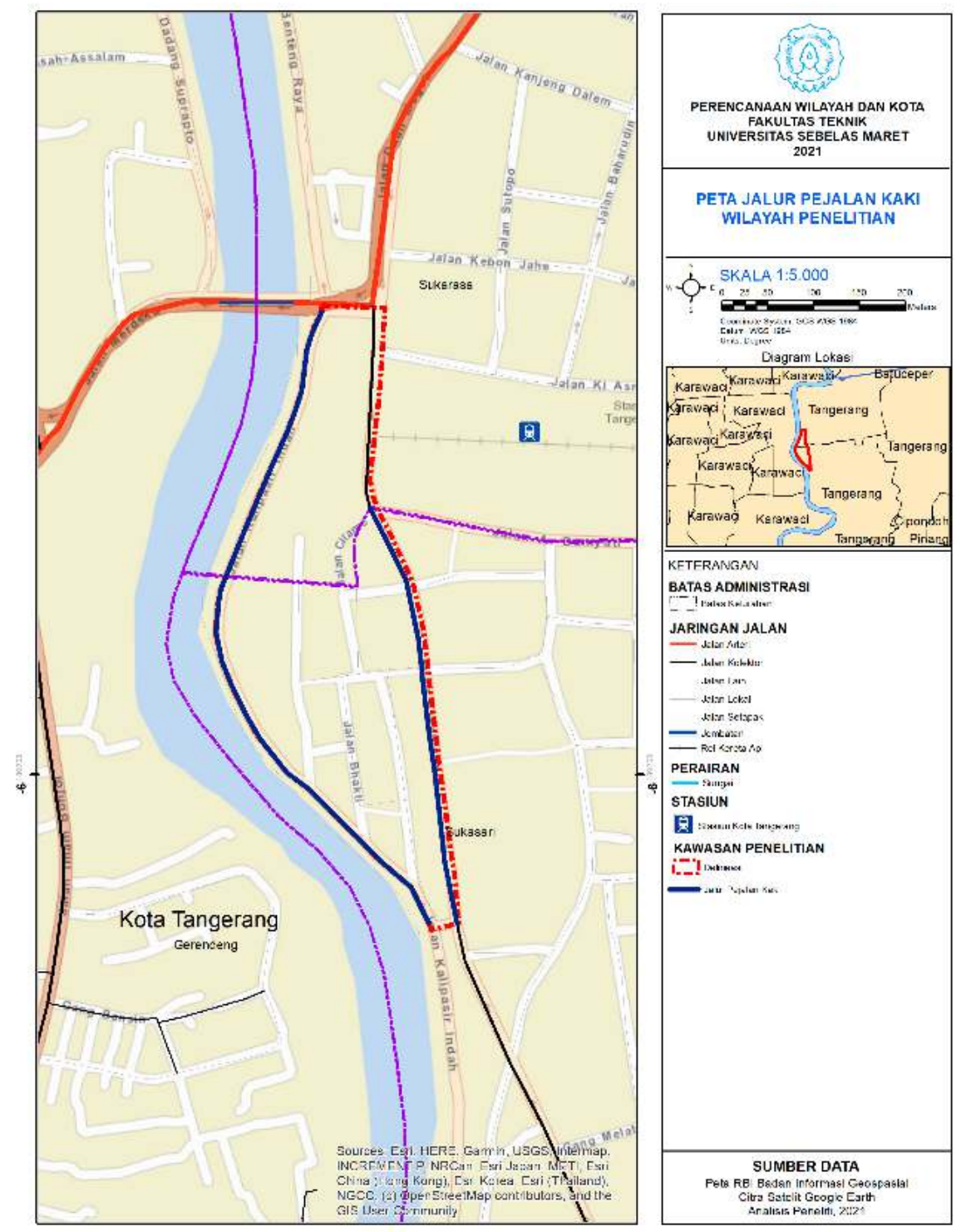

Gambar 11. Peta Jalur Pejalan Kaki Kawasan Pecinan Kota Lama Tangerang

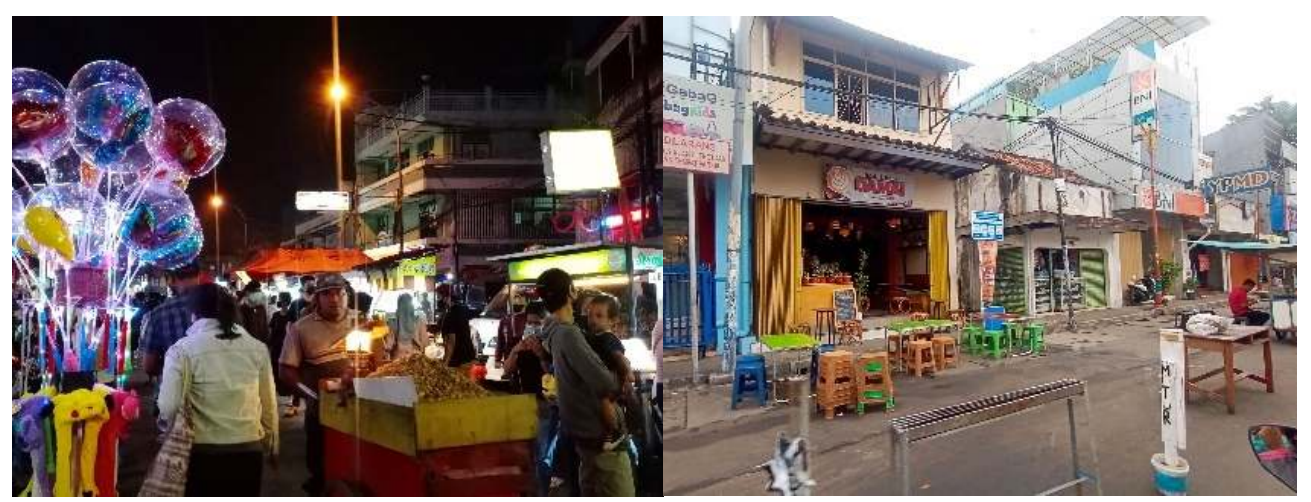

Gambar 12. Kondisi Eksisting Jalur Pejalan Kaki di Zona Kuliner 


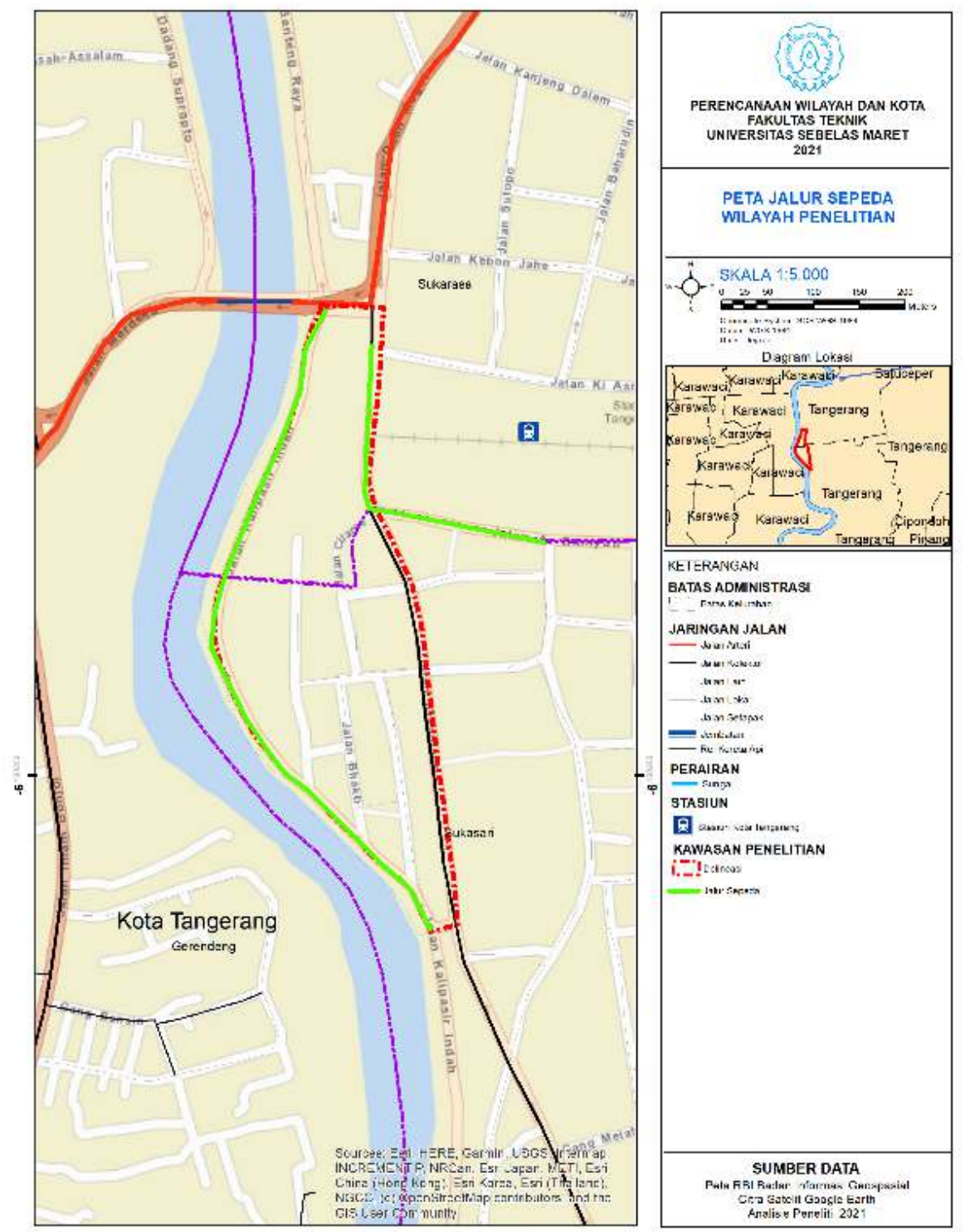

Gambar 13. Peta Jalur Sepeda Kawasan Pecinan Kota Lama Tangerang

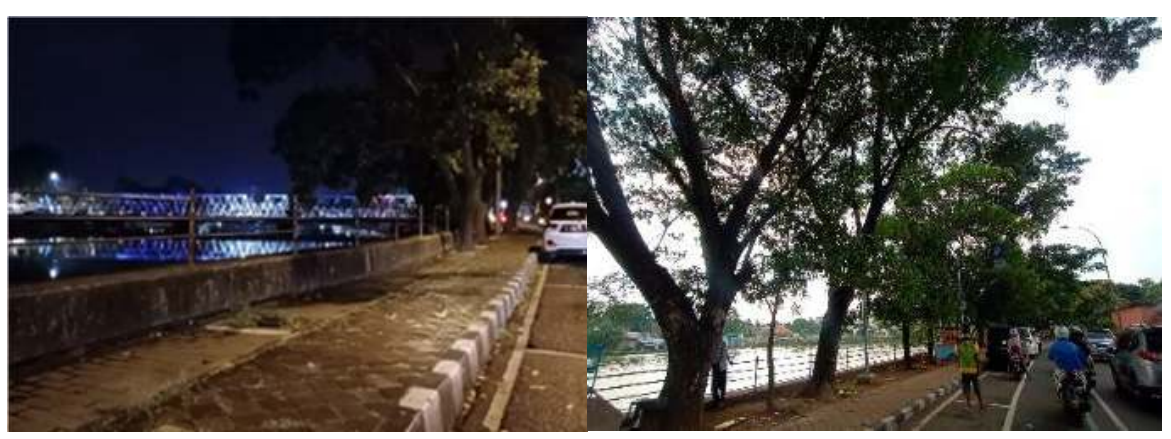

Gambar 14. Kondisi Eksisting Jalur Pejalan Kaki 


\section{Simpulan}

Kawasan Pecinan Kota Lama Tangerang merupakan kawasan yang memiliki nilai penting dalam perkembangan Kota Tangerang. Pada kawasan ini terdapat banyak sejarah dan obyek wisata perdagangan kuliner. Dengan adanya hal tersebut kawasan pecinan menjadi ramai dikunjungi oleh masyarakat dalam dan luar Kota Tangerang untuk berkunjung dan menikmati. Namun, terdapat permasalahan yang ada di kawasan ini terjadi karena padatnya pengunjung dan kurangnya lahan parkir yang menyebabkan adanya kemacetan dan terganggunya jalur pejalan kaki dikarenakan pedagang kaki lima. Tingginya mobilitas yang ada menjadikan kawasan pecinan harus memiliki sistem sirkulasi dan jalur-jalur penghubung serta transportasi umum yang memudahkan pengunjung untuk bersirkulasi dan menikmati kawasan pecinan sebagai kawasan wisata Kota Tangerang.

Saran untuk pengembangan Kawasan Pecinan Kota Lama Tangerang yaitu perlunya perbaikan dan penataan ulang kawasan agar menjadi lebih terintegrasi dan dapat mendukung kawasan menjadi obyek pariwisata. Meningkatkan kualitas Kawasan Pecinan Kota Lama Tangerang dengan melakukan perbaikan fisik melalui revitalisasi, preservasi dan konservasi. Meningkatkan kualitas urban street furniture untuk memperkuat karakter kawasan. Serta pengembangan sarana dan prasarana pendukung di kawasan pecinan yang kurang ataupun belum tersedia pada kawasan seperti lahan parkir, lahan kegiatan aktivitas belanja dan kuliner sehingga tidak memakai jalur pejalan kaki dan badan jalan.

\section{Daftar Rujukan}

[1] S. Fauzia and A. Ratnasari R, "Pengaruh Aktivitas Kawasan Terhadap Sirkulasi Lalu Lintas di Kawasan Jalan Pandanaran," Jurnal Teknik PWK, vol. 2, no. 3, pp. 875-884, 2013.

[2] Nurlisa Ginting and Selamat Sejahtera, "Elemen Sirkulasi Dan Parkir Pada Penataan Koridor Jamin Ginting-Brastagi," Jurnal Koridor, vol. 9, no. 1, pp. 143-149, 2019, doi: 10.32734/koridor.v9i1.1325.

[3] W. S. N. W. Mohamad and I. Said, "A review of variables of urban street connectivity for spatial connection," IOP Conference Series: Earth and Environmental Science, vol. 18, no. 1, 2014, doi: 10.1088/1755-1315/18/1/012173

[4] J. Peponis, D. Allen, S. French, M. Scoppa, and J. Brown, "Street Connectivity And Urban Density," Proceedings, 6th International Space Syntax Symposium, Istanbul, 2007, pp. 4.1-4.12, 2007.

[5] A. Widodo, "Studi Tentang Kenyamanan Pejalan Kaki Terhadap Pemanfataan Trotoar Di Jalan Protokol Kota Semarang (Studi Kasus Jalan Pandanaran Semarang)," Jurnal Teknik Sipil \& Perencanaan, vol. 15, no. 1, pp. 1-12, 2013, doi: 10.15294/jtsp.v15i1.7109.

[6] M. P. Umum, "Pedoman Umum Rencana Tata Bangunan dan Lingkungan," no. 06, 2007.

[7] H. Andi Halim, "Analisa Ruang Publik Koridor Jalan Ratulangi Di Makassar," LOSARI : Jurnal Arsitektur Kota dan Pemukiman, pp. 29-33, 2016, doi: 10.33096/losari.v1i1.34.

[8] R. E. Santoso, S. R. Sari, and S. Rukayah, "Sirkulasi manusia dan kendaraan pada pedestrian terhadap koneksitas simpang lima semarang," Jurnal Arsitektur $A R C A D E$, vol. 4, no. 1, p. 35, Mar. 2020, doi: 10.31848/ARCADE.V4I1.321. 